Article

\title{
Air Transportation Income and Price Elasticities in Remote Areas: The Case of the Brazilian Amazon Region
}

\author{
Rodrigo V. Ventura ${ }^{1,2, *}$, Manoela Cabo ${ }^{1,3, *}$, Rafael Caixeta ${ }^{4}$, Elton Fernandes ${ }^{2}$ and \\ Vicente Aprigliano Fernandes 5 (i) \\ 1 IBGE Brazilian Institute of Geography and Statistics, Rio de Janeiro 20031170, Brazil \\ 2 COPPE Production Engineering Program, UFRJ Federal University of Rio de Janeiro, \\ Rio de Janeiro 21941450, Brazil; elton@pet.coppe.ufrj.br \\ 3 COPPE Transportation Engineering Program, UFRJ Federal University of Rio de Janeiro, \\ Rio de Janeiro 21941450, Brazil \\ 4 MCA Trade, Rio de Janeiro 22775005, Brazil; rafael.caixeta@mcalub.com.br \\ 5 Instituto de Geografia, Pontificia Universidad Católica de Valparaíso, Valparaíso 2362807, Chile; \\ vicente.aprigliano@pucv.cl \\ * Correspondence: rodrigo.ventura@ibge.gov.br (R.V.V.); manoela.cabo@ibge.gov.br (M.C.)
}

Received: 19 June 2020; Accepted: 14 July 2020; Published: 28 July 2020

\begin{abstract}
The literature, aimed at understanding the income-price elasticity of air passenger demand, bases its analysis on airport movement. The diversity of studies regarding the casualty between air transportation and economic growth are examples. Some studies covering this link, estimate the income-price relationship with the demand considering international traffic. Considering a domestic setting, where this traffic is significant in Brazil, studies related to remote regions are scarce, and the existing ones focus on governmental policies and subsidies. In addition, empirical studies on the theme consenter themselves in developed regions, such as Europe, North America, and Australia. For Brazil, where we find the Amazon region, there is no empirical research. This paper analyses the price-income elasticity of the demand regarding domestic passengers in air links from remote cities of the Brazilian Amazon. This study uses panel data regression analysis method on a database of domestic scheduled flights of Brazil's National Civil Aviation Agency. The results show that air passengers involving remote region flights present a lower sensitivity regarding local income and an airline's price variations than those in flights among capitals. The higher difference is in the income elasticity of the remote city of origin, which is lower than that of the air traffic among capitals.
\end{abstract}

Keywords: air transportation; Brazilian Amazon; demand; elasticity; isolated cities

\section{Introduction}

The structural analysis of the aviation market and the process of price formation of airlines within their business strategy implantation has been an object of great academic interest [1]. However, the literature targeted to comprehend price-income elasticity of demand for passenger air transportation is still limited [2], especially when consider the fact that the sensitiveness of the demand for air transportation and oscillations in prices and income may vary according to the travel characteristics [3-6].

Despite being important to investigate the price-income elasticity of the demand to comprehend the consumer's decision-making process, the low number of studies regarding this issue is understandable because of the shortage of databases containing information on the airfares marketed for the passengers' real origin and destination [3]. This limitation hinders estimations for elasticity, making it difficult 
to be calculated beyond the average value of the aviation industry in general, compromising the comprehension of different factors affecting it.

Studies regarding the elasticity in relation to remote cities are also rare, especially in developing countries, where the air transportation assumes an even more strategic character in virtue of the long-distance travel necessary to ensure connectivity with the rest of the world. This is the case of the interior cities of Brazil's North region. Almost the total area of Amazon is located in this region. In addition to the fact of concentrating the biggest biodiversity of the planet, having a central role in the global warming control and in any policy agendas related to the promotion of the sustainable development [7], the Amazon is also individualized by its logistic void. Interior cities in this region are difficult to access through other means of transportation than the airplane; thus, fluvial transportation is the most common alternative to it and, to lesser extent, the road transportation, both insufficient and presenting low quality.

In this paper, our goal is to analyze the income-price elasticity of the demand regarding domestic passengers in air links from remote or isolated cities of the Brazilian Amazon. The objective is to discuss such elasticities according to the correspondent elasticities among state capitals of the country, emphasizing the differences found and the necessary factors for the implementation of policies regarding the development of the regional air transportation activity. On the other hand, in a market environment, without subsidies for airlines and passengers, the comprehension of the income-price relationship with the passengers demand is essential for the decision-making concerning the implementation of air links by the companies of the sector.

In order to estimate the income-price elasticity of the passenger demand, this paper uses a methodology of panel data regression analysis for two groups. The first one involves the links with origin in remote cities of the country's North region, while the second involves the links among the capitals of Brazilian states. This analysis achieves a special robustness of character in virtue of the provision, by the National Civil Aviation Agency of Brazil (ANAC), of a sample with origin and destination data regarding domestic passengers of regular aviation, as well as the airfares effectively commercialized for each travel, starting in 2011.

In the North region, which is larger than India in territorial extension (it would be the seventh largest in the world if it were a country), the regular domestic air traffic of passengers adopts complex characteristics among its interior cities, within the intra- and inter-regional scope, which requires a bigger comprehension among these passenger flows and local economy. In addition of having as case of study a region of international interest and almost unexplored in analysis, which is the Brazilian Amazon, other special characteristic of this paper is that it considers an openness period of the Brazilian economy and subsequent liberalization of air transportation. For this reason, in addition to estimate and discuss the factors affecting the sensitiveness of the demand regarding the passenger air transportation and the variations in price and income, this paper explores the discussion of market conditions, which, in a liberal scenario, will have a greater influence in the decision of airlines in operating in isolated areas. Abate [8], for example, pointed out that the liberalization of the airline sector in Africa resulted in a $40 \%$ increase in the frequency of flights, but had no impact on prices. This reinforces the importance of studying how demand behaves in relation to price changes under different market conditions.

The following items of the article are organized this manner: Item 2 shows a review of the articles considered as relevant for the definition of an analytical methodology adequate to the study of remote cities; Item 3 describes the methodology adopted; Item 4 contextualizes the case of the North region of Brazil, evidencing its geographic characteristics and the socioeconomic profile; Item 5 presents the data used in the research through descriptive statistics; Item 6 depicts and discusses the results regarding the application of the methodology; and, concluding, Item 7 ends and presents indications for future research. 


\section{Materials and Methods}

\subsection{Literature Review}

The literature review will focus on a set of articles selected to support the definition of the paper's methodology. The existing approaches aim to scrutinize the passenger air market as a whole (for example, in airports), using the function of demand aggregated by the service as a base of analysis [9]. The literature related to the theme of this paper is focused on the investigation of geographical, socioeconomic and market factors, which explain a higher (or lower) income-price elasticity of demand regarding passenger air transportation, as well as the formation of prices related to this service under a microeconomic perspective $[3,4,10,11]$.

In general, studies regarding aviation and remote locations are interwoven with regional aviation studies, focusing on the question of subsidies. Then, the following government programs are highlighted: Public Service Obligation (PSO), Social services provided by state-owned airlines, and Essential Air Service (EAS). Such studies are concentrated in specific regions of Asia, Australia, Europe and North America, locations with a transportation network more developed and more integrated than the one found in remote regions of Latin America countries [12-14].

Brons et al. [3] investigated the determinants regarding the price elasticity of demand on the passenger air transportation sector, aiming to identify the common factors supporting the different estimations found in the literature for the elasticity. The investigation is based on the meta-analysis in which 37 studies were considered, where one or more estimations for the price elasticity of demand regarding passenger air transportation were calculated, leading to a total of 204 observations concentrated in North American, Europe and Australia air markets. In the analysis, they consider the elasticity estimations as the dependent variable to be explained by geographical, economic and demographic variables, which information is obtained in each original study investigated. The authors conclude that, in fact, the price elasticity of demand may vary according to the nature of the travel, the existence or not of other substitute transportation modes, the geographical location for which the elasticity is calculated and cultural differences. Brons et al. [3] also point out that the omission of the income variable in the models analyzed introduce a bias in the estimations of price elasticity of demand, suggesting that it must be systematically maintained in these types of studies.

Bråthen [12] mapped and analyzed seven strategic questions related to the air transportation in remote regions: the need of government support; economies of scale and ticket price process; airport costs and operational costs of airlines; the subsidies level, barriers to entrance and competitiveness in the market environment; bidding process and risk sharing; and remote areas and regional development. The analysis is limited to remote areas within the scope of USA (Essential Air Service) and Canada (Public Service Obligation) government subsidy programs. The author concludes that the quality of the business environment for the promotion of investments in the air transportation system is as relevant as the subsidy policy for the economic development of isolated regions.

Granados et al. [4] studied the variation of the price elasticity of demand regarding passenger air transportation due to the different forms of commercialization (online versus traditional) and due to the different purposes of the travel (leisure versus business). Using a database containing 2.21 million of flight tickets commercialized in USA between September 2003 and August 2004 for 47 different routes among North American cities, the empirical analysis used an estimation of ordinary least squares from which it was concluded that, in general, consumers are more sensitive to price variations in markets where research costs are lower, once they have a greater access to the offer of substitute services. The greater access to information causes an increase in the competition through the internet, which enables the offer of alternative services inside and outside the airway mode. The authors concluded that the online demand is more elastic than the offline, for passenger air transportation with either the purpose of holiday or business. In addition to this, Granados et al. [4] report that passengers 
travelling for leisure present a more elastic demand in relation to the variation in prices than the ones travelling for business.

Bråthen and Halpern [13] analyzed the air transportation in remote regions with the purpose of mapping the critical questions and bottlenecks that must be surpassed so that the sector contributes to the regional economic development in a more efficient form. The authors performed a literature review on the theme and investigated the experience of government programs in Europe and North America. The discussion is limited to situations in which the offer of regional air transportation is only feasible by means of subsidies. They highlight that, in addition to the subsidies, the public policies must be capable of impacting the market environment and operational costs of airlines as an integral part of a regional development strategy sustained by the air transportation system.

You and Xiong [10] empirically analyzed the sensitiveness of the demand regarding passenger air transportation in China and fluctuations in the income level of the resident population. Considering that there is a strong correlation between the passenger air transportation and economic development, the authors sought to estimate the income elasticity of demand for the Chinese aviation market. They analyzed annual data aggregated for China from the total number of passengers transported by the airlines departing from the country and the available income per capita regarding the resident population between 1995 and 2015. You and Xiong [10] obtained evidence that the demand concerning passenger air transportation in China is elastic in relation to the income for the greater part of the period considered by the research. From the results obtained, the authors conclude that, with the accelerated economic growth experienced by China in the last years, the passenger air transportation is becoming, gradually, more popular inside the country.

Wang et al. [11] sought to analyze the determinants of the price formation process and the demand regarding passenger air transportation in the two most populous and fastest-growing economic countries in the last decades: China and India. Although both countries present many similarities in several areas, there are substantial differences among their air transport sectors. Private and low-cost airlines dominate the Indian aviation market, while government-controlled airlines are the main operators of the Chinese market. The authors analyzed data regarding the main domestic routes inside each country. The sample for India includes the routes connecting the 20 most populous cities of the country, while for China, routes connecting the 20 largest domestic airports were selected. 4387 observations were considered for the Indian market and 7865 for the Chinese, which were collected on a monthly basis for the period of January 2012 to December 2015. Wang et al. [11] used an approach of two-stage least squares, from which the price elasticities of the demand, based on a function of structural demand, were estimated. The results reported that the price elasticity of demand in the Indian passenger air sector (estimated in 2.6) is approximately double that of the one recorded in China (1.2). The authors conclude that the greater intra-modal competition in the Indian market, with a higher ingress of low-cost airlines, is a key-factor to explain the higher sensitivity of demand to price variations when compared to the most concentrated Chinese market.

Fageda et al. [14] investigated the influence of prices and frequencies of different public policies regarding the aerial connectivity in remote regions. The authors highlight that the potential positive impacts of such policies must be considered in relation to their costs, once the volume of public subsidies may be very elevated. Fageda et al. [14] reinforces that the public policies must play a strategic role in the support to the connectivity in remote areas.

The literature shows that the sensitiveness of demand for air transportation and the oscillations in prices and income may vary according to the characteristics of travel and economic, demographic and geographic factors, which defines its context; in general, studies on the fluctuation of price-income elasticity of demand throughout the time and their determinants have as a study objective the passenger air transportation as a whole, and focus on international links or air traffic related to the busiest passenger lines. However, the importance of the sector is even higher when it comes to the remote regions, where the air transportation is strategic due to the long-distance travels necessary to connect them to the rest of the world. That way, the lack of studies regarding elasticity in remote regions raises 
the question: how would this relation be in these locations in which the civil aviation is a key element of the transportation system?

Added to this, is the lack of specific studies regarding the Latin America region presenting a huge territorial diversity, in which the Brazilian Amazon stands out. Located in the macro-region of the North of Brazil, it is a region of international interest by its role in the planet and relevance for the sustainable development. Fenley et al. [15] discuss the development models in the region, evidencing that the air transportation may play an important role for the sustainability of the Amazon development. Regarding the analytical methodology of the studies, it is observed that the panel data regression analysis has become adequate.

\subsection{Methodology}

The behavior of prices and income during the last decades, featured by constant variations and some abrupt changes, makes the use of temporal series beneficial for the calculation of estimations regarding price-income elasticities of the demand for passenger air transportation [3]. In addition to the time dependency, the price analysis considers the real origin-destination $(\mathrm{O}-\mathrm{D})$ of air links, connecting isolated cities, situated in remote areas, with other locations. By virtue of the temporal dependence of explanatory variables, price and income, and with the availability of information for a set of units (O-Ds) under the form of cross-section, the technique of panel data was used.

Known also as longitudinal data, this approach is characterized by repeated observations of a given set of units in cross-section. Therefore, the panel refers to data with the same cross-section units throughout the time. In this, the interest, predictor and explanatory variables are measured on different occasions, commonly, throughout the time, for a same individual or element (in the case of this study, the air links). It is worth mentioning that, in longitudinal studies, the observations of an individual throughout the time are correlated, and the technical statistics considering this dependence are necessary [16]. Among the benefits of the panel data analysis, the possibility of studying the dynamic relations throughout the time and modelling the differences among the individuals is highlighted [17].

It is important to note that, in this study, only links coming from interior (remote) cities of the Brazilian North region are considered the target for the analysis. The links between capitals of Brazilian states (mentioned in this article as trunk-links) are employed as an analysis reference.

The standard linear model used for longitudinal data may be defined by:

$$
Y=X \mathrm{~B}+\mathrm{E}
$$

where,

$$
Y_{N T x 1}=\left[\begin{array}{c}
Y_{1} \\
\vdots \\
Y_{N}
\end{array}\right], X_{N T x k}=\left[\begin{array}{c}
X_{1} \\
\vdots \\
X_{N}
\end{array}\right], \mathrm{E}_{N T x 1}=\left[\begin{array}{c}
\mathrm{E}_{1} \\
\vdots \\
\mathrm{E}_{N}
\end{array}\right], \mathrm{B}_{k x 1}=\left[\begin{array}{c}
\beta_{1} \\
\vdots \\
\beta_{N}
\end{array}\right]
$$

where,

$$
Y_{i}=\left[\begin{array}{c}
Y_{j 1} \\
\vdots \\
Y_{j T}
\end{array}\right], X_{i}=\left[\begin{array}{ccc}
X_{j 11} & \ldots & X_{j k 1} \\
\vdots & \ddots & \vdots \\
X_{j 1 T} & \ldots & X_{j k T}
\end{array}\right], \mathrm{E}_{i}=\left[\begin{array}{c}
\mathrm{E}_{j 1} \\
\vdots \\
\mathrm{E}_{j N}
\end{array}\right], \quad \begin{aligned}
& i=1, \ldots, N, \\
& j=1, \ldots, n .
\end{aligned}
$$

The assumptions made by this model correspond to the ones defined by the classic model of multiple linear regression, however this one does not use the structure of panel data. Therefore, the errors must be independent and identically distributed (iid), in addition to homoscedasticity, i.e., for a given individual, the observations are not correlated and, between individuals and time, the variance of the error is constant.

However, the advantage of using the panel data structure is to obtain the analysis of the individuals' behavior in the course of time, resulting in the existence of differences among them [17]. This disadvantage may be interpreted as a bigger similarity among observations of the same individual 
when compared to other individual. The failure in the inclusion of this factor to the model may cause problems of bias in estimators.

Thus, a new model is proposed, which presents a differentiated structure for the term of error, assuming that the differences among the units may be captured through differences in the constant term:

$$
Y_{i t}=X_{i t} \mathrm{~B}+\varepsilon_{i t}, \varepsilon_{i t}=\alpha_{i}+\mathrm{N}_{i t}, \mathrm{~N}_{i t} \sim \operatorname{iid}\left(0, \sigma^{2}\right) .
$$

Therefore, the equation is summarized in:

$$
Y_{i t}=\alpha_{i}+X_{i t} \mathrm{~B}+\mathrm{N}_{i t}
$$

In this formulation, $\alpha_{i}$ represents the individual effect, presenting variation among individuals and constancy over time, while $\mathrm{N}_{i t}$ ranges regardless of the individual or time. It is possible to capture the heterogeneity among individuals with a model characterized by this manner [18]. This model, however, may be segmented in others according to the assumptions made regarding the individual effect.

Then, the hypothesis of a fixed or aleatory annual effect must be tested in the model selection. Other important aspect is the characteristic of each link between two airports.

In the panel data analysis, it is necessary to consider in the modelling the existence of fixed or aleatory effects of cross-sections-in this study, the O-Ds of passengers-and the time series of data. In order to select the most appropriate model, the following tests are performed: redundant fixed effects (Chow test), omitted random effects (Breusch-Pagan test) and correlated random effects (Hausman test) [19].

The dependent variable considered in the model is the number of seats sold (PAX), representing the demand for air transportation. The independent variables are the GDP (Gross domestic product) of the origin city (GDPO) and destination city (GDPD), representing the income, and the weighted-average fare of the tickets in the link (PRICE), representing the price. For the purposes of this paper, it is assumed that GDP is the variable that best represents the total income of the economy in remote cities. The appropriate effects of each $\mathrm{O}-\mathrm{D}$ and each period are defined according to the results suggested by the statistical tests performed (fixed or aleatory effects). The tool used to perform the regressions was the econometric software for statistical modelling, Eviews 11 [20].

All variables are related to the annual data, and, regarding the fare, it is the weighted average in the link. The general model used to estimate the regression parameters is shown in Equation 6. The presence of cross-section effects was significant from the statistical tests performed in the process of selection concerning the most appropriate model.

$$
\ln P A X_{i, j, t}=c+\omega_{i, j}+\alpha \ln G D P O_{i, j, t}+\beta \ln G D P D_{i, j, t}+\varphi \ln P R I C E_{i, j, t}+\varepsilon_{i, j, t}
$$

where,

c: constant

ln: the natural logarithm of the variables;

$\omega_{i, j}$ : estimated fixed effect coefficients of cross-sections;

$\alpha, \beta$ and $\gamma$ : estimated coefficients in regression model;

$\mathrm{GDPO}_{i, j, t}$ : GDP of the origin city;

$G D P D_{i, j, t}:$ GDP of the destination city;

PRICE $_{i, j, t}$ : weighted-average fare of $\mathrm{O}-\mathrm{D}$;

$\varepsilon_{i, j, t}:$ regression error.

It is worth mentioning that the two-stage method with instrumental variable could be adequate to correct the possibility of endogeneity of price variable, however a limitation of the paper is to find an instrumental variable for remote regions. 


\section{Results}

\subsection{Case Study}

Brazil is a country with continental dimensions, classified as the world's fifth-largest country in geographical extension and seventh in population size [21-23]. The country is organized under a form of a federative republic composed by 26 states and a Federal District (the nation's capital), distributed in 5 macro-regions (Appendix A-Annex 1). The North is one of these macro-regions and comprises seven states: Acre (AC), Amapá (AP), Amazonas (AM), Pará (PA), Rondônia (RO), Roraima (RR), and Tocantins (TO). Its biggest and main cities are the capitals Manaus (AM) and Belém (PA), the only ones with a population of more than one million inhabitants [22]. The following state capitals are also important regional centers: Porto Velho (RO), Macapá (AP), Palmas (TO), Rio Branco (AC), and Boa Vista (RR).

The North has the largest territorial extension among the five macro-regions, covering approximately $45 \%$ of the national territory. Amazonas is the largest Brazilian state. It exceeds the sum of the territories of South and Southeast macro-regions. The largest Brazilian municipality is Altamira, in Pará, which is larger than several Brazilian states. The ten cities with the largest territorial dimension in Brazil are located inside the Amazon region [21]. On the other hand, the North region population, accounts for only $9 \%$ of the national total. Consequently, the North presents the lower population density among the largest regions of the country [22].

The economy of the region contributes with 5.6\% of the Brazilian GDP. Five out of the six states presenting the lowest GDPs of Brazil are in the North region. Thus, the economic density and the GDP per capita of the region are also below the national average [24].

The major part of the so-called Legal Amazon is located in the North region (Legal Amazon is comprised by the seven states which are part of the North region, by the state of Mato Grosso, that is included in the Central-West region, and by the cities of the Maranhão state, part of the Northeast region, that are located at east of the meridian $44^{\circ}$. Legal Amazon covers about $61 \%$ of the Brazilian territory [25]). This is a region of international interest due to its relevance and role regarding the sustainable development of the planet. Its growing importance in the worldwide agenda concerning sustainability is due to the carbon stock, weather, water, and biodiversity existing in the region [26].

Amazon has the largest drainage basin of the planet (one fifth of the world's freshwater reserves) and comprises one of the greatest biodiversity in the world (one-third of the world's broadleaf forest reserve), which makes the region strategic for the global weather regulation [7,27]. Among the potentialities of Amazon, we highlight the mineral reserves found in the region, with emphasis in iron ore, manganese, niobium, oil, and natural gas [26].

Table 1 illustrates the socioeconomic profile of the North region in comparative terms to the national average.

Table 1. Socioeconomic profile of the North region and Brazilian Legal Amazon: comparative analysis with the national average.

\begin{tabular}{|c|c|c|c|c|c|c|c|c|c|c|c|}
\hline \multirow{2}{*}{ Region } & \multicolumn{2}{|c|}{$\begin{array}{l}\text { Cities, } \\
2019\end{array}$} & \multicolumn{2}{|c|}{$\begin{array}{l}\text { Area, } \\
2018\end{array}$} & \multicolumn{2}{|c|}{$\begin{array}{l}\text { Population, } \\
2019\end{array}$} & \multicolumn{2}{|c|}{$\begin{array}{l}\text { GDP, } \\
2017\end{array}$} & \multirow{2}{*}{$\begin{array}{c}\text { Population } \\
\text { Density } \\
(\text { inhab./km²) }\end{array}$} & \multirow{2}{*}{$\begin{array}{l}\text { Economic Density } \\
\text { (BRL Thousand } / \mathbf{k m}^{2} \text { ) }\end{array}$} & \multirow{2}{*}{$\begin{array}{l}\text { GDP Per Capita } \\
\text { (BRL Thousand) }\end{array}$} \\
\hline & No. & $\%$ & $\begin{array}{l}\text { Millions } \\
\text { km }^{2}\end{array}$ & $\%$ & $\begin{array}{l}\text { Millions } \\
\text { Inhab. }\end{array}$ & $\%$ & $\begin{array}{c}\text { BRL } \\
\text { Billions }\end{array}$ & $\%$ & & & \\
\hline North & 450 & 8 & 3.8 & 45 & 18 & 9 & 367.9 & 5.6 & 4.7 & 96.8 & 20.6 \\
\hline $\begin{array}{c}\text { Legal } \\
\text { Amazon }\end{array}$ & 772 & 14 & 5.0 & 59 & 27 & 13 & 574.8 & 8.7 & 5.4 & 114.5 & 21.2 \\
\hline
\end{tabular}

Source: IBGE-Brazilian Institute of Geography and Statistics.

The North region presents the most humid weather in Brazil, with a period of a large volume of rains, flooding several areas and roads, which makes access only possible by air. Consequently, since the arrival of the first colonizers to the Brazilian territory, it may be verified that the occupation of 
Amazon has, as one of its main bottlenecks, the precarious link to the rest of the country [28]. It is in this Amazonian immensity that the logistics, especially with regard to transportation, face big challenges and barriers to be operationalized, due to the characteristics of the region. The large distances to be crossed are combined to the deficiencies existing in different modes [29].

The study of Territory Flows and Networks, performed by the Brazilian Institute of Geography and Statistics (IBGE) [29], points out an uneven distribution of the density regarding transport logistics network between the North region and the rest of the country, resulting in a complete isolation of certain areas of Brazilian Amazon (Appendix A-Annex 3). In Brazil, the road mode in the transportation logistics prevails; however, the Amazon region is an exception to this rule. In the North region, the passengers water transportation prevails and the distances among municipal capitals are long, resulting in long journey times. The interaction among urban centers became rare once the transportation is predominantly performed through waterways and is, therefore, slower, considering the fact that the municipal capitals are distant.

The air modal is essential in the transportation logistics of the North region. The regional highway network is insufficient, with low quality and poorer integration, which makes the North states more dependent of the aviation system for the socioeconomic development and for humanitarian activities [29]. In 2019, 59\% of Brazilian roads were assessed as regular, bad, or terrible in a research performed by the Brazilian National Confederation of Transport (CNT). In the North region, this percentage was even higher: $77 \%$ [30].

Table 2 shows some statistics related to the regular domestic air transportation in remote cities of the North region of Brazil for the period analyzed.

Table 2. Evolution regarding the coverage of regular domestic air transportation in remote locations of the Brazilian North region.

\begin{tabular}{cccccc}
\hline Year & Cities & PAX & POP (Millions) & GDPO (BRL Billions) & PRICE (BRL) \\
\hline 2011 & 31 & 633,805 & 2.526 & 73.793 & 290.31 \\
\hline 2012 & 28 & 680,136 & 2.340 & 69.380 & 311.63 \\
\hline 2013 & 27 & 781,275 & 2.376 & 73.399 & 300.41 \\
\hline 2014 & 26 & 755,907 & 2.335 & 64.237 & 355.40 \\
\hline 2015 & 26 & 746,508 & 2.409 & 58.180 & 323.32 \\
\hline 2016 & 20 & 482,963 & 2.084 & 50.112 & 314.15 \\
\hline \multicolumn{7}{c}{ Source: ANAC micro data }
\end{tabular}

It is observed that the number of cities covered by regular air transportation reduces over the years, minimizing the population quantitative (POP) potentially covered by the civil aviation system. This reduction indicates the optimization of routes by companies and the search for profitability in operations related to air routes in remote regions.

The reduction in the total of passengers boarding in airports of the region (PAX) is a result of two movements: first, the economic crisis experienced by the country in the second half of the period, visible in the GDP reduction in remote cities (GDPO), and the second, the reduction of the service offer regarding the air transportation according the lowest number of cities served. The price analysis of air tickets (PRICE) considers the weighted average of fares practiced in each link of the sample. In order to allow a better comparison among the years, all monetary values used in the study were deflated. The average price of tickets was directly influenced by the behavior of the Brazilian economy in the period. Between 2012 and 2014, the Brazilian GDP recorded an average growth of $+1.8 \%$ per year. This rhythm was reduced to an average variation of $-3.4 \%$ per year in 2015 and 2016.

Some developments occurred during the period under investigation that affected airline decisions and demand for air travel. In 2011, the country was experiencing an environment of political stability and economic growth. The start of the concession of the major Brazilian airports, the choice of the 
country to host the FIFA Football World Cup held in 2014 and the choice of Rio de Janeiro to host the Olympic Games held in 2016, among other factors, leads to a feeling of optimism regarding the evolution of air transport in Brazil. This climate of positive economic outlook continued until 2014, when a process of economic and political crisis began in the country, culminating in the impeachment of the president at the end of 2016. Although there is an increase in passenger demand from 2011 to 2013 , from about $23 \%$, there is already a reduction in the cities served by air transportation, which is accentuated until 2016 with the reduction in travel demand in the study region.

\subsection{Data}

The air transportation data used in this study-information regarding origin and destination $(\mathrm{O}-\mathrm{D})$ of seats sold and prices of air tickets-is obtained in ANAC microdata base (available at: www.anac. gov.br/assuntos/dados-e-estatisticas/microdados-de-tarifas-aereas-comercializadas), which comprises the value of the fare effectively commercialized and the volume of seats sold per link and per level of fare, per month, in the period from 2011 to 2016. The year 2011 is the first from which information on the airline fares is available by route. In addition, in 2011 the first round of concessions from large Brazilian airports for private management was consolidated.

The first step in the sample preparation was the identification of the isolated cities and the annualization of the movement data among $\mathrm{O}-\mathrm{Ds}$ and the calculation of the weighted average fare in each link per year. The analysis of the Brazilian territory indicates the North region as the one presenting the largest number of cities located in isolated and remote regions, concentrated in the so-called Legal Amazon.

Although a category can always be broken down into subcategories, we are considering the Amazon as a homogeneous region in relation to air transport in its remote cities, whose differences between locations are explained by the dummy variables of each route. This procedure was also adopted in relation to the movement between capital cities.

According to ANAC, this data represents around $50 \%$ of the total movement in each year, once the tickets purchased through frequent-flyer programs and specific agreements celebrated between purchasers and airlines do not integrate the basis. The socioeconomic data used in the study, i.e., the GDP regarding the origin and destination municipalities of the travels contained in the sample, are obtained from IBGE. In this sense, it is worth mentioning that the data referring to the cities GDP has a lag of two years, so that 2016 is the last year for which they were available at the time this paper was produced.

The database is directional, i.e., it considers the one-way ticket from the interior (remote) city of the North region to intra and interregional destinations. The data refers to the 33 airports with $1372 \mathrm{O}-\mathrm{Ds}$ validated for the analysis in the period. Appendix A presents the map of Brazilian regions, with the location of airports considered in the study (Annex 2), as well as the ICAO acronym of airports, the cities related to each one of them and the identification of the name regarding the corresponding Brazilian state (Table A1).

The analysis model will investigate the relation among four variables, two representing the regular aviation and two representing the economy. The first is the PAX natural logarithm of the city classified as remote or isolated for other in the national territory (LPAX), and the second is the natural logarithm of the average fare applied in air links of the sample (LPRICE). The other two variables represent the economic context through natural logarithms of GDPs of origin (LGDPO) and destination (LGDPD) cities. Table 3 shows the descriptive statistics of the variables considered for analysis in the model.

The standard average and deviation of the LPAX variable indicate an accentuated variety of flow in links of remote cities. The small standard deviation observed in LPRICE indicates a certain uniformity in the price of tickets. This is because these cities, in general, are distant from economic centers, at distances not so diversified. The difference observed between LGDPO and LGDPD is because the latter includes the economic centers interacting with remote cities. The small standard deviation of both indicates a small size variation of cities. 
Table 3. Descriptive statistics of the model variables.

\begin{tabular}{ccccc}
\hline & LPAX & LGDPO & LGDPD & LPRICE \\
\hline Mean & 3.67 & 14.60 & 16.60 & 6.75 \\
Maximum & 11.47 & 17.20 & 20.41 & 8.34 \\
Minimum & 0.00 & 11.64 & 10.76 & 3.68 \\
Std. Dev. & 2.41 & 1.09 & 1.72 & 0.47 \\
Observations & 5231 & 5231 & 5231 & 5231 \\
\hline
\end{tabular}

Some selected cities are touristic cities or cities presenting strategic interest for the country. Tabatinga, in Amazonas state, for example, is a city bordering Colombia, with the city of Leticia beside it-strategic city for the control of Brazilian borders. Tucuruí, in Pará state, is the host city of the municipality where one of the biggest hydroelectric plants in Brazil is located. Santarém, also in Pará state, is a historic city, founded in 1661, which is located at the junction of the Amazonas and Tapajós rivers. Ourilândia do Norte is a city in a mining area in Pará state. Parauapebas, as well in Pará state, is settled in one of the biggest mineral provinces of the planet called Serra dos Carajás, with iron ore, manganese, copper and gold reserves. Coari, in Amazonas state, where there is a significant production of natural gas. Parintins, also in Amazonas state, holds the Parintins Festival (Festa do Boi), which is an annual famous manifestation of the local culture acknowledged and appreciated internationally. In general, each city has an attractive feature which demands more efficient transportation, where public and private interests are connected.

\subsection{Results}

As described in the methodology, Chow, Breusch-Pagan and Hausman tests were applied for the definition of the effects regarding the model used (no effect or pool, fixed effects and aleatory effects). The Chow test (Table 4) rejected (value of $p<0.05$ ) the null hypothesis of pool estimation for the cross-section, suggesting that the fixed effects would be more appropriate.

Table 4. Redundant fixed effects tests (Chow test).

\begin{tabular}{cccc}
\hline \multicolumn{4}{c}{ Test Cross-Section and Period Fixed Effects } \\
\hline Effects Test & Statistic & d.f. & $p$-Value \\
\hline Cross-section F & 11.29 & $-13,713,856$ & 0.00 \\
Cross-Section/Period F & 8434.62 & 1371 & 0.00 \\
\hline
\end{tabular}

The Breusch-Pagan test (Table 5), performed with the purpose of verifying the presence of aleatory effects versus no effect (pool), also rejected the null hypothesis of the pool modelling (value $p<0.05$ ), suggesting, in this case, that the aleatory effect would be more appropriate.

Table 5. Lagrange Multiplier Tests for Random Effects (Breusch-Pagan LM).

\begin{tabular}{cccc}
\hline & \multicolumn{3}{c}{ Test Hypothesis } \\
\cline { 2 - 4 } & Cross-Section & Time & Both \\
\hline Breusch-Pagan & 4220.44 & 136.29 & 4356.74 \\
\hline$p$-value & 0.00 & 0.00 & 0.00 \\
\hline
\end{tabular}

The next step was the application of the Hausman test. The purpose of this test is to compare the estimation of aleatory effects with the ones of fixed effects. Significant differences among them suggest the inconsistency of aleatory effects estimators. The results of Hausman test (Table 6) point out that the null hypothesis for aleatory effects (value of $p<0.05$ ) is rejected, recommending that the modelling developed considers the existence of fixed effects for transversal sections and periods. 
Table 6. Correlated Random Effects-Hausman Test.

\begin{tabular}{cccc}
\hline Test Summary & Chi-Sq. Statistic & Chi-Sq. d.f. & $\boldsymbol{p}$-Value \\
\hline Cross-section random & 76.093436 & 3 & 0.00 \\
\hline
\end{tabular}

Therefore, the selection process of the most adequate estimator for the proposed analysis in this work pointed out, in this order, that: a model of fixed effect would be more appropriate than the pool approach (Chow test); analogously, an aleatory effect model would be more appropriate than the pool approach (Breusch-Pagan test); and, finally, that the fixed effect model would be more appropriate than the aleatory effect for the section and period (Hausman test). The fixed effect of the period was not considered, bearing in mind the fact that the historical series is six years. Thus, after examining different possible options, the regression model of ordinary least squares with panel data and with fixed effect in cross-section was selected as the most appropriate estimator for this analysis.

Table 7 shows the results of the regression model applied, containing the GDPO, GDPD and PRICE elasticities of the demand (LPAX) in O-Ds of remote cities. Dummies with positive coefficients indicate the most attractive routes for air transport and the elasticities portray what can be expected from demand for the hypotheses of price and income variations.

Table 7. Remote Cities Elasticity—Panel least squares regression model.

\begin{tabular}{|c|c|c|c|}
\hline \multicolumn{4}{|c|}{ Dependent Variable: $\ln (\mathrm{PAX})$} \\
\hline \multicolumn{4}{|c|}{ Cross-Section Fixed (Dummy Variables) } \\
\hline \multicolumn{4}{|c|}{ Total Panel (Unbalanced) Observations: 5231} \\
\hline Variable & Coefficient & t-Statistic & Prob. \\
\hline $\ln (\mathrm{GDPO})$ & 0.66 & 6.74 & 0.00 \\
\hline $\ln (\mathrm{GDPD})$ & 0.55 & 3.23 & 0.00 \\
\hline $\ln (\mathrm{PRICE})$ & -0.93 & -18.26 & 0.00 \\
\hline $\mathrm{C}$ & -8.88 & -2.99 & 0.00 \\
\hline Adjusted R-squared & & 0.821 & \\
\hline
\end{tabular}

The explanation level of estimated model (Adjusted R-square) is reasonable for the passengers' flow in O-Ds of remote cities, given the complexity of estimation. Statistical tests confirm the significance of the income indicators regarding the cities involved in $\mathrm{O}-\mathrm{D}$, and the ticket price. All coefficients were inelastic, i.e., lower than 1 . However, if we consider the two income indicators ranging together in the same direction, an income elasticity higher than 1 may be observed. If they range in different directions, one may cancel the other. The price elasticity of the demand is almost unitary, so that in the case of remote cities, a variation in the demand of an $\mathrm{O}-\mathrm{D}$ in the same proportion of the price may be expected.

Figure 1 shows the dummy variation of the cross-section fixed effects of remote cities, sorted in ascending order. It shows that the introduction of this dummy absorbed the effect of density difference regarding O-Ds of the sample, allowing the model to estimate the real effect on the passengers demand, from the variations in the income of cities, and from the price of air tickets. The basic motivation for the implantation of links with remote cities will always occur by specific motivators, isolated or jointly, among the $\mathrm{O}-\mathrm{D}$ locations, as: tourism, energetic resources, mining, agricultural activities, migrations, regional development policies, national defense logistics, among others. 


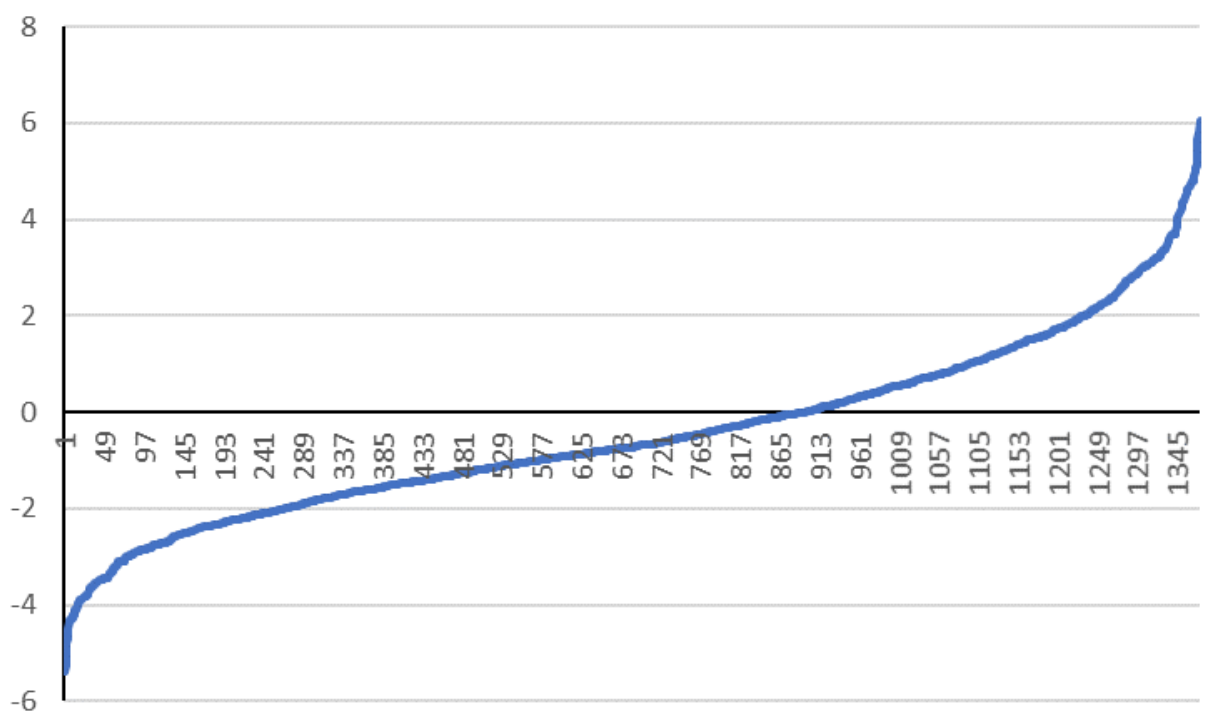

Figure 1. Cross-section fixed effects remote cities.

\section{Discussion}

For purposes of comparative analysis and discussion, the same model of regression was applied in the trunk-links, or among capitals. Table 8 shows the results for such links. In this case, $865 \mathrm{O}-\mathrm{Ds}$ with valid data were identified.

Table 8. Main Trunk Elasticity—Panel least squares regression model.

\begin{tabular}{|c|c|c|c|}
\hline \multicolumn{4}{|c|}{ Dependent Variable: LPAX } \\
\hline \multicolumn{4}{|c|}{ Cross-Section Fixed (Dummy Variables) } \\
\hline \multicolumn{4}{|c|}{ Total Panel (Unbalanced) Observations: 5141} \\
\hline Variable & Coefficient & t-Statistic & Prob. \\
\hline LGDPO & 1.15 & 10.54 & 0.00 \\
\hline LGDPD & 0.62 & 7.11 & 0.00 \\
\hline LPRICE & -1.03 & -32.63 & 0.00 \\
\hline $\mathrm{C}$ & -15.89 & -7.51 & 0.00 \\
\hline Adjusted R-squared & & 0.956 & \\
\hline
\end{tabular}

The model of O-Ds among capitals (Table 8) shows a level of explanation higher than the one of remote cities (Table 7), observed in the Adjusted R-square of 0.956. All explanatory variables of the demand (LPAX) present statistical tests confirming the significance of estimated coefficients. Figure 2 shows the same characteristics of Figure 1 for the capitals. It is observed that few links have a large adjustment promoted by the dummy. This is due to the case of positive adjustment to the O-D observations with the cities of São Paulo, Rio de Janeiro, and Brasília. In case of negative adjustments, they are applied to links with state capitals of less developed states, as Roraima and Tocantins.

Different from the remote cities model, the income elasticity of demand in relation to the city of origin is higher than 1, i.e., elastic. The result of trunk lines is similar to the one observed in You and Xiong [10], which obtained evidence that the demand for passenger air transportation in China is elastic in relation to the income for the majority of the period considered in the research (1995-2015). This illustrates that the economic development of the capital cities makes civil aviation more popular, which is reflected in the proportionally greater increase in the air transport flow of its residents. The income elasticity of the destination city in the demand, on the other hand, is close in both estimated cases. Although it is bigger than the one for remote cities, the income elasticity for 
the destination city is still lower than 1, i.e., inelastic demand. An issue that should be noted is the neutralizing effect in relation to the evolution of the demand that the drop in the income of one of the link cities may have on the growth of the other.

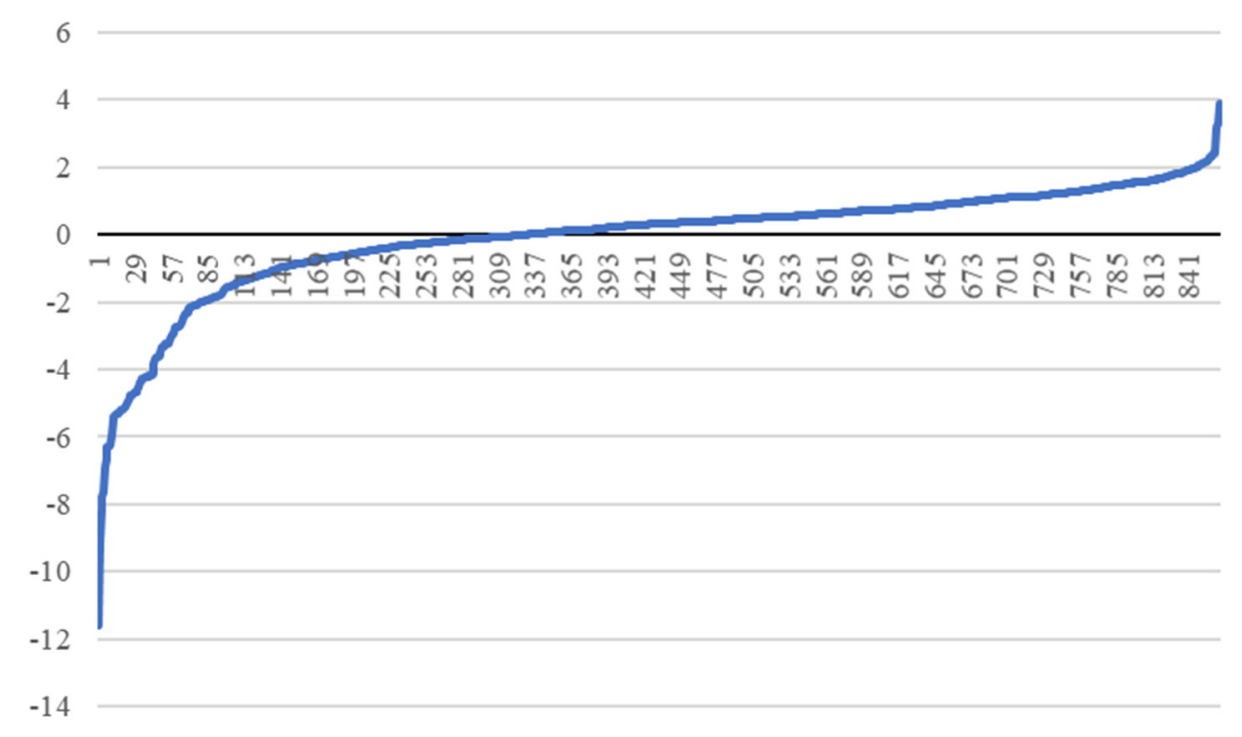

Figure 2. Cross-section fixed effects capital cities.

According to the report from Brazilian Secretariat of Civil Aviation [31], most parts of domestic air travels in the North region of the country are for business/study purposes. This finding indicates a lower sensitivity to price, mainly in remote cities, where there is no competition of other modes and, in many cases, only one company is able to offer the service. Consequently, the estimation of non-elasticity price regarding the demand in remote cities is expected. The movement among capitals presents a small price elasticity, which may be interpreted as an inefficiency of the Brazilian market, which shows a low competitiveness in the sector. Brazil presents one of the lowest price elasticities of demand among the estimations of related studies. For example, Brons et al. [3], considering 37 studies regarding air links in North America, Europe, and Australia, found values for price elasticity of demand concentrated in the range of 1.0 to 2.0. Mumbower et al. [6], considering the main North American airlines, estimated in 1.97 the price elasticity of the demand. Wang et al. [11], upon assessing the main airports and cities of China and India, conclude that, in the Chinese market, this elasticity is 1.2 , while in Indian market is 2.6.

The geographical extent and the logistical void of the Brazilian North region are other important explanatory factors for the different estimations regarding price-income elasticity of demand, since, like the purpose of the trip, they act directly on the essentiality of air transport for the consumer. The possibility of alternative modes of transportation and, consequently, the value of elasticities is directly related to the access difficulty. Long distances and difficulties of construction regarding terrestrial accesses, due to the geographical conditions of Amazon, are associated to less alternative possibilities of displacement, resulting in a greater stiffness in the demand regarding air transportation to variations in price and income [3].

Differences among the income-price elasticities of demand regarding links between capitals and remote cities may be considered by planners and decision makers in the air transportation sector, under penalty of having their demand expectations frustrated, mainly in the case of remote cities. When investigating the air network in Africa, an exemplar of a very sparse market, where thin flows typically result in infrequent air service at very high costs, Ssamula [32] highlights the importance of the elasticity of demand for the success of initiatives aimed at making air connections between remote cities profitable. The author points out that the impact of a redesign of the air network on the 
profitability of such routes depends directly on the sensitivity of demand to variations in the fares that will result from this initiative.

\section{Conclusions}

Results show that the demand for passenger air transportation for links coming from remote cities of Brazilian Amazon is inelastic to variations in price and income. This is an important factor for the planning of the air transportation in the region, once the major part of studies indicates elasticities bigger than 1 of these two items. The difference between the results obtained for routes coming from remote areas and capital cities routes shows the need to have a regional look in order to outline plans for the future.

Other important evidence is that the income has a bigger influence than the ticket price on the decision regarding the use of air transportation. The separation between income effect of the origin city and destination city offers a new perspective to the planner, once future scenarios regarding the income evolution may differ from one city to another.

Although the estimations of the representativity regarding price income elasticity of demand related to the air transportation are lined up with other studies, it is observed that, in Brazil, such elasticities are found in the lowest levels observed in the literature. This indicates a fragility in the country regarding the competitiveness in the domestic air market. The standardization of the fleet of Brazilian airlines in large airplanes [33] may be a limiting factor to the competition in low-density routes.

Therefore, this paper also contributes for the analysis of the demand behavior for passenger air transportation in a market situation without the presence of subsidies. In the analyzed period, companies do not receive any incentive to operate in isolated cities and there are no substantial improvements in airport infrastructure based on government actions. Otherwise, passengers are also not given any direct encouragement to use air transport. Considering these conditions, in this scenario the companies choose the cities and routes that guarantee the profitability of the operation without subsidy and pay the airport and aeronautical tariffs according to the Government's determinations. It offers elements for the discussion regarding the market conditions, which will have a major influence in the decision of airlines to operate in remote areas.

In a market environment, without subsidies for airlines and passengers, the comprehension of the price-income relation with the demand of passengers is essential for the decision making related to the implementation of air links by the companies of the sector, as well as for the implementation of policies for the development of the regional air transportation activity. In addition to subsidies, the public policies must be capable of developing the market environment for the airlines as an integral part of a regional development strategy for the Brazilian Amazon, leveraged by the air transportation system.

The research on air transportation and remote cities in the Latin America is still limited and has relevance on different aspects, and the most prominent of them is the environmental concern regarding the occupation of areas as the Brazilian Amazon. However, the sustainability of the development requires the concern with the environment to be always combined with the socioeconomic agenda, which is what defines people's living conditions. In the study line of this article, it may be suggested that an item to be strongly discussed would be the identification of some seasonal pattern for the behavior of elasticities according to the characteristics of the region. The analysis may be also enhanced by some segmentation related to the travel motivation (business versus tourism) and the behavior of the elasticities for each passenger profile.

Author Contributions: Conceptualization, E.F.; Formal analysis, E.F., M.C., R.C., R.V.V. and V.A.F.; Funding acquisition, E.F., M.C., R.C., R.V.V. and V.A.F.; Investigation, E.F., M.C., R.C., R.V.V. and V.A.F.; Project administration, M.C. and R.V.V.; Writing-original draft, E.F., M.C., R.C., R.V.V. and V.A.F.; Writing-review and editing, E.F., M.C., R.C., R.V.V. and V.A.F. All authors have read and agreed to the published version of the manuscript.

Funding: This research received no external funding. 
Acknowledgments: The authors would like to thank the editor and anonymous reviewers for their insightful comments and suggestions.

Conflicts of Interest: The authors declare no conflicts of interest.

\section{Appendix A}

Annex 1

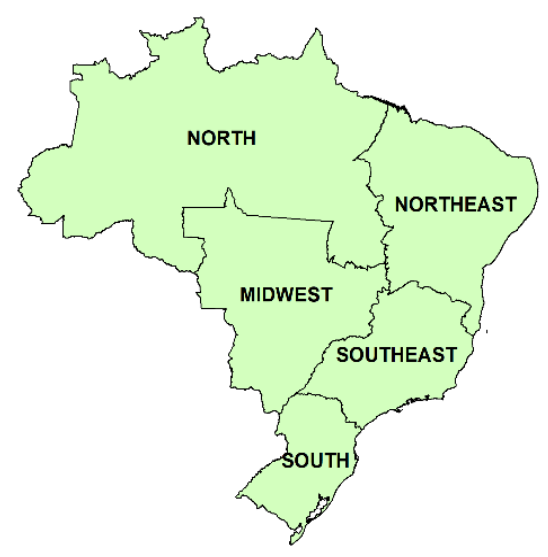

Figure A1. Macro-regions of Brazil.

\section{Annex 2}

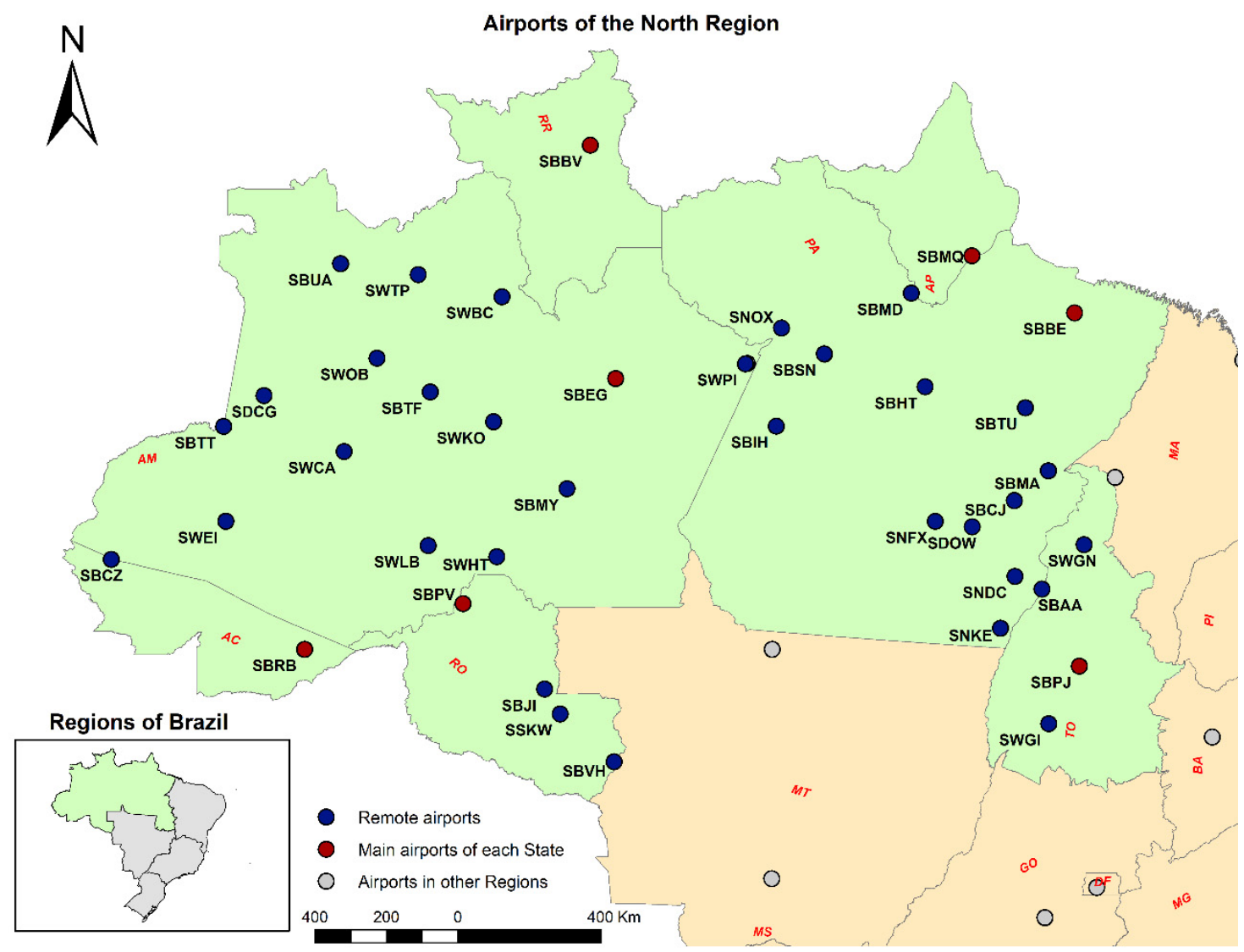

Figure A2. Location of the Brazilian North region airports with regular air transport during the period of analysis. 
Annex 3

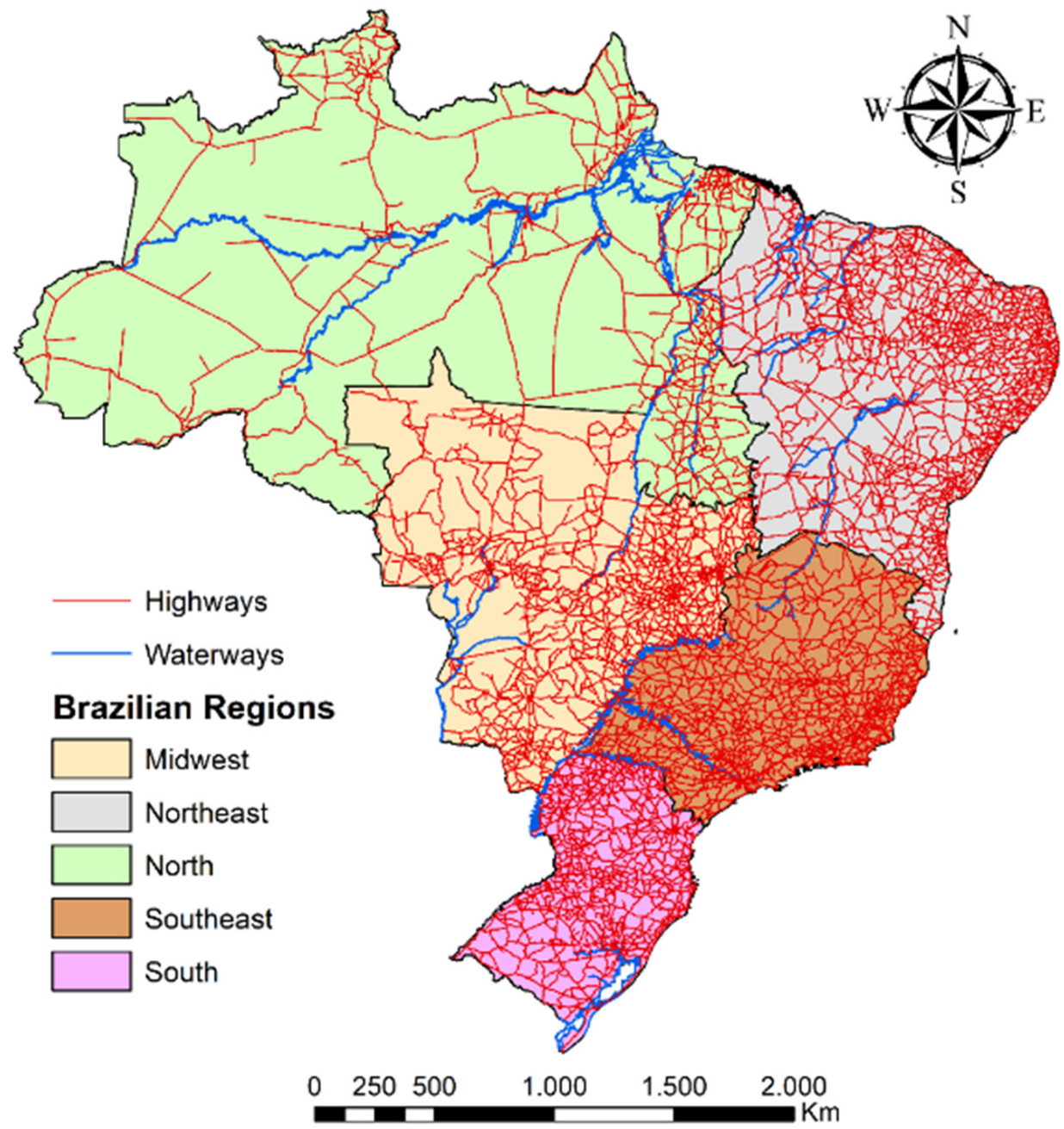

Figure A3. Infrastructure of roadways and waterways in Brazil [34].

Table A1. Airports in each city. State and number of cities of North region-ID related to Figure A2.

\begin{tabular}{cccc}
\hline ICAO & City/County & State & $\begin{array}{c}\text { Number of } \\
\text { Cities/Counties }\end{array}$ \\
\hline SBCZ & Cruzeiro do Sul & Acre (AC) & 1 \\
\hline SWBC & Barcelos & & \\
SWCA & Carauari & & \\
SWKO & Coari & & \\
SWEI & Eirunepé & \\
SWOB & Fonte Boa & \\
SWHT & Humaitá & \\
SWLB & Lábrea & \\
SBMY & Manicoré & \\
SWPI & Parintins & \\
SWTP & Santa Isabel do Rio Negro & & \\
SBUA & São Gabriel da Cachoeira & & \\
SDCG & São Paulo de Olivença & & \\
SBTT & Tabatinga & \\
SBTF & Tefé & \\
\hline
\end{tabular}


Table A1. Cont.

\begin{tabular}{cccc}
\hline ICAO & City/County & State & $\begin{array}{c}\text { Number of } \\
\text { Cities/Counties }\end{array}$ \\
\hline SBMD & Almeirim & & \\
SBHT & Altamira & & \\
SBAA & Conceição do Araguaia & & \\
SBIH & Itaituba & & \\
SBMA & Marabá & & \\
SNOX & Oriximiná & & \\
SDOW & Ourilândia do Nó (PA) & \\
SBCJ & Parauapebas & & \\
SNDC & Redenção & & \\
SNKE & Santana do Araguaia & & \\
SBSN & Santarém & & \\
SNFX & São Félix do Xingu & & \\
SBTU & Tucuruí & & \\
\hline SSKW & Cacoal & & \\
SBJI & Ji-Paraná & Rondônia (RO) & \\
SBVH & Vilhena & & \\
\hline SWGN & Araguaína & Tocantins (TO) & \\
SWGI & Gurupi & & \\
\hline
\end{tabular}

* In this study, the municipality host city has the same name of the municipality, and the socioeconomic data are those regarding the municipality.

\section{References}

1. Morlotti, C.; Cattaneo, M.; Malighetti, P.; Redondi, R. Multi-dimensional price elasticity for leisure and business destinations in the low-cost air transport market: Evidence from easyJet. Tour. Manag. 2017, 61, 23-34. [CrossRef]

2. Bijmolt, T.; van Heerde, H.; Pieters, R. New empirical generalizations on the determinants of price elasticity. J. Mark. Res. 2005, 42, 141-156. [CrossRef]

3. Brons, M.; Pels, E.; Nijkamp, P.; Rietveld, P. Price elasticities of demand for passenger air travel: A meta-analysis. J. Air Transp. Manag. 2002, 8, 165-175. [CrossRef]

4. Granados, N.; Gupta, A.; Kauffman, R. Online and offline demand and price elasticities: Evidence from the air travel industry. Inf. Syst. Res. 2012, 23, 164-181. [CrossRef]

5. Granados, N.; Kauffman, R.; Lai, H.; Lin, H. À la carte pricing and price elasticity of demand in air travel. Decis. Support Syst. 2012, 53, 381-394. [CrossRef]

6. Mumbower, S.; Garrow, L.; HigginsM. Estimating flight-level price elasticities using online airline data: A first step toward integrating pricing, demand, and revenue optimization. Transp. Res. Part A Policy Pract. 2014, 66, 196-212. [CrossRef]

7. Garda, A.A.; da Silva, J.M.C.; Baião, P.C. Biodiversity conservation and sustainable development in the Amazon. Syst. Biodivers. 2010, 8, 169-175. [CrossRef]

8. Abate, M. Economic effects of air transport market liberalization in Africa. Transp. Res. Part A Policy Pract. 2016, 92, 326-337. [CrossRef]

9. Oum, T.; Waters, W.; Yong, J. Concepts of price elasticities of transport demand and recent empirical estimates: An interpretative survey. J. Transp. Econ. Policy 1992, 26, 139-154.

10. You, K.; Xiong, J.E.F. Airline passenger numbers impact analysis based on the income elasticity. In Proceedings of the International Conference on Computer Engineering, Information Science and Internet Technology (CII 2017), Sanya, China, 11-12 November 2017; pp. 560-565.

11. Wang, K.; Zhang, A.; Zhang, Y. Key determinants of airline pricing and air travel demand in China and India: Policy, ownership, and LCC competition. Transp. Policy 2018, 63, 80-89. [CrossRef]

12. Bråthen, S. Air transport services in remote regions. Int. Transp. Forum Discuss. Pap. 2011, 13, 1-23.

13. Bråthen, S.; Halpern, N. Air transport service provision and management strategies to improve the economic benefits for remote regions. Res. Transp. Bus. Manag. 2012, 4, 3-12. [CrossRef] 
14. Fageda, X.; Suárez-Alemán, A.; Serebrisky, T.; Fioravanti, R. Air transport connectivity of remote regions: The impacts of public policies. Reg. Stud. 2019, 53, 1161-1169. [CrossRef]

15. Fenley, C.A.; Machado, W.V.; Fernandes, E. Air transport and sustainability: Lessons from Amazonas. Appl. Geogr. 2007, 27, 63-77. [CrossRef]

16. Twisk, J.W. Applied Longitudinal Data Analysis for Epidemiology: A Practical Guide; Cambridge University Press: Cambridge, UK, 2013.

17. Frees, E.W. Longitudinal and Panel Data: Analysis and Applications in the Social Sciences; Cambridge University Press: Cambridge, UK, 2004.

18. Johnston, J. Econometric Methods, 3rd Edition. J. Appl. Econom. 1988, 3, 252-254.

19. Hsiao, C. Analysis of Panel Data; Cambridge University Press: Cambridge, UK, 2014.

20. Eviews. Eviews 11 User's Guide II-Instrumental Variables; In: Eviews 11; IHS Global Inc.: London, UK, 2019.

21. IBGE. Área dos Municípios 2018. Available online: https://www.ibge.gov.br/geociencias/organizacao-doterritorio/estrutura-territorial/15761-areas-dos-municipios.html? $\mathrm{t}=$ acesso-ao-produto\&c=1 (accessed on 1 June 2020).

22. IBGE. Estimativas da População Residente para os Municípios e para as Unidades da Federação com Data de Referência em $1^{\circ}$ de Julho de 2019. Available online: https://biblioteca.ibge.gov.br/index.php/bibliotecacatalogo?view=detalhes\&id=2101662 (accessed on 1 June 2020).

23. CIA. The World Factbook 2020; Central Intelligence Agency: Washington, DC, USA. Available online: https://www.cia.gov/library/publications/resources/the-world-factbook/index.html (accessed on 1 June 2020).

24. IBGE. Produto Interno Bruto (PIB) Dos Municípios 2017. Available online: https://biblioteca.ibge.gov.br/ index.php/biblioteca-catalogo?view=detalhes\&id=2101688 (accessed on 1 June 2020).

25. IBGE. Amazônia Legal. Available online: https://www.ibge.gov.br/geociencias/organizacao-do-territorio/ estrutura-territorial/15819-amazonia-legal.html?=\&t=acesso-ao-produto (accessed on 1 June 2020).

26. Araújo, R.; Léna, P. Desenvolvimento Sustentável e Sociedades na Amazônia; Museu Paraense Emilio Goeldi: Belém, Pará, Brazil, 2011.

27. Kauano, E.E.; Silva, J.M.C.; Diniz Filho, J.A.F.; Michalski, F. Do protected areas hamper economic development of the Amazon region? An analysis of the relationship between protected areas and the economic growth of Brazilian Amazon municipalities. Land Use Policy 2020, 92, 1-12. [CrossRef]

28. Lima, W.T.; Silva, I.O.; Sousa, L.F. Breve Retrospectiva das Estratégias Geopolíticas de Incorporação Territorial da Amazônia Brasileira. RAEGA O Espaço Geográfico em Análise 2012, 24, 18-37.

29. IBGE. Ligações Rodoviárias e Hidroviárias 2016. Available online: https://biblioteca.ibge.gov.br/index.php/ biblioteca-catalogo?view=detalhes\&id=2100617 (accessed on 1 June 2020).

30. CNT. Anuário CNT do Transporte: EstatíSticas Consolidadas 2019. Available online: https:// anuariodotransporte.cnt.org.br/2019/ (accessed on 1 June 2020).

31. SAC—Secretaria de Aviação Civil da Presidência da República, 2014. O Brasil que voa. Available online: http://transportes.gov.br/obrasilquevoa/pdf/Relatorio_Executivo_O_Brasil_que_Voa_v4.pdf (accessed on 1 June 2020).

32. Ssamula, B. Comparing air transport network operations in sparse networks in Africa. Res. Transp. Bus. Manag. 2012, 4, 22-28. [CrossRef]

33. Cabo, M.; Fernandes, E.; Alonso, P.; Pacheco, R.R.; Fagundes, F. Energy Effectiveness of Jet Fuel Utilization in Brazilian Air Transport. Sustainability 2020, 12, 303. [CrossRef]

34. IBGE. Logística dos Transportes. Available online: https://www.ibge.gov.br/geociencias/organizacao-doterritorio/redes-e-fluxos-geograficos/15793-logistica-dos-transportes.html?=\&t=downloads (accessed on 1 June 2020).

(C) 2020 by the authors. Licensee MDPI, Basel, Switzerland. This article is an open access article distributed under the terms and conditions of the Creative Commons Attribution (CC BY) license (http://creativecommons.org/licenses/by/4.0/). 